Wiaam M.O. AL-Ashou BDS., MSc. (Lec.)

\section{Fracture Resistance of Roots After Canal Preparation by Two Methods and Obtu- rated by Different Techniques}

Dept. of Conservative Dentistry

College of Dentistry, University of Mosul

$$
\begin{aligned}
& \text { الأهداف: تحف الدراسة الخبرية إلى تحديد تأثير أنواع الأدوات (اليدوية و الميكانيكية) وتقنيات عتتلفة من حشوات الجذر ( الثرمافيل، والتكثيف الجانبي) على }
\end{aligned}
$$

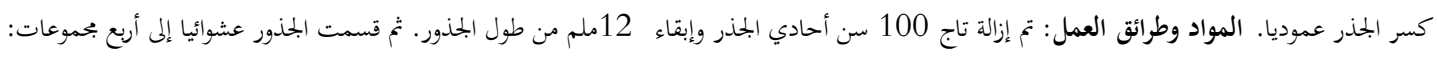

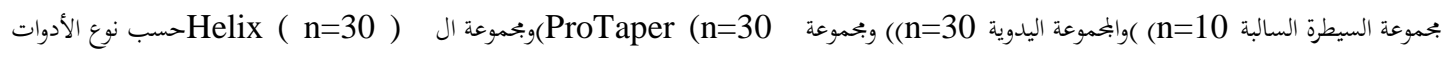

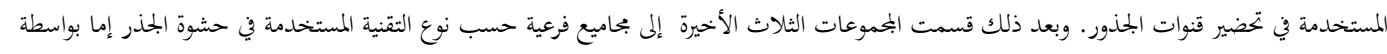

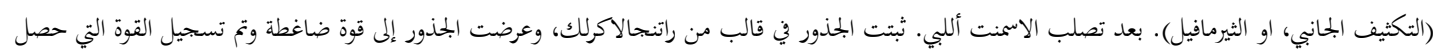

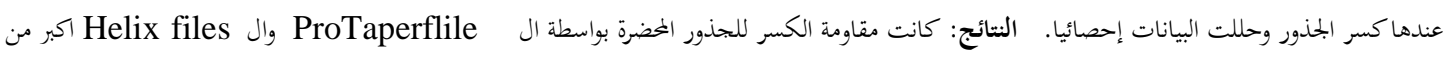

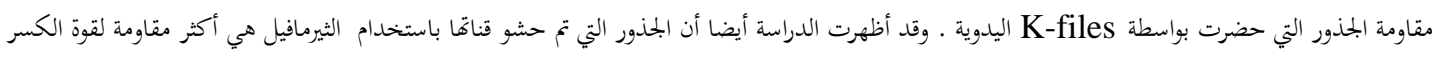

$$
\begin{aligned}
& \text { من الجذور التي تم حشو قناتما باستخدام التكثيف الجانبي ولكن الفرق ليس معنويا بين البحموعتين. الاستنتاجات: استخدام مبارد النيكل تيتانيوم الدوارة بحعل الجذور } \\
& \text { أكثر مقاومة للكسر وان طريقة التكثيف الجانبي تضعف الجذر وبتعله أكثر عرضة للكسر ألعامودي. }
\end{aligned}
$$

\title{
ABSTRACT
}

Aims: The purposes of this in vitro study are to investigate the effect of instrumentation types ( hand and rotary instrumentations) and obturation techniques (Cold lateral, and Thermafil) on vertical root fracture. Materials and Methods: The crown of the 100 single rooted teeth were removed leaving $12 \mathrm{~mm}$ of the roots length, then the root randomly divided into four groups. Control -ve Group(n=10), Hand Group(n=30), ProTaper Group $(n=30)$ and Helix Group $(n=30)$ according to the type of the instrument used to prepared the root canals. After that, the last three groups subdivided into subgroups according to the obturation technique either by using Cold Lateral condensation technique or Thermafil obturation technique. After the sealer set, the roots were embedded in acrylic moulds and subjected to compressive loading, the load at which the fracture occurred was recorded and statically analysis. Results: the fracture resistance of the root prepared by Helix and ProTaper files were significantly greater than that obtained for the root canals prepared with hand K-files. The results of this study also demonstrated that when root canals obturated with Thermafil the roots resist the fracture load greater than that of the canals obturated with Cold Lateral condensation obturation but the difference is not statistically significant between them. Conclusions: the use of rotary nickel titanium files in endodontic treatment provides higher fracture resistance for the roots, and the use of the Cold Lateral condensation obturation technique may weaken the roots, so that the roots become more susceptible to the vertical root fracture.

Key words: Fracture resistance, Rotary ProTaper files, Root canal obturation, Thermafil, Lateral condensation.

AL-Ashou WM, Fracture Resistance of Roots After Canal Preparation by Two Methods and Obturated by Different Techniques. Al-Rafidain Dent J. 2014; 14(2):212-219 .

Received: 17/2/2013 Sent to Referees: 26/2/2013 Accepted for Publication: 16/4/2013

\section{INTRODUCTION}

Vertical root fractures (VRFs) in endodontically treated teeth are the most serious complications. VRFs had a poor prognosis, usually result in tooth extraction. ${ }^{(1)}$ Causes of root fractures have been thought to be related to root canal preparation, root canal filling, post preparation, and post placement. ${ }^{(2,3,4)}$
Advancements of rotary nickel titanium (NiTi) instruments over the last decade have lead to new design concepts and techniques of canal preparation. In order to improve working safety, shorten preparation time and create a continuously tapered, conical flare of preparations, advanced instrument designs with non cutting tips, radial lands superior resistance to 
tensional fracture and varying tapers have been developed. ${ }^{(5)}$ Increase canal taper advocated by various taper rotary nickel titanium (NiTi) instruments has allowed different canal shapes and sizes to be achieved, most of new systems have tapering greater than the ISO standard 0.02 taper design. Rotary nickel titanium instrument are now available with tapers ranging from (0.04 to 0.12$)$ up to now little is known about the influence of instrument taper on the fracture resistance of the tooth roots. ${ }^{(6,7)}$

Lateral compaction of gutta-percha is widely used to fill the root canal system and was reported previously to be associated with an increased risk of VRF. ${ }^{(8)}$ Spreader design and applied forces were suggested as contributing factors to the appearance of VRF during lateral compaction. ${ }^{(9)}$ However, laboratory stress distribution studies consistently conclude that the pressure applied during lateral compaction is insufficient to cause VRF. ${ }^{(10,11)}$ Thus, it remains unclear whether lateral compaction can cause VRF. As an alternative, several techniques like Thermafil and Single-cone where no compaction forces are to used have been proposed and shown to produce an apical seal similar to that of lateral compaction when used with dimensionally stable sealers. ${ }^{(11)}$

The purposes of this study are to determine the effect of instrumentation types (hand and rotary instrumentation) and obturation technique (Cold lateral, and Thermafil) on vertical root fracture.

\section{MATERIALS AND METHODS}

One hundred extracted, straight, single rooted mandibular premolar teeth were selected and stored in distilled water. The teeth with root caries, apical resorption or previous root canal treatment were discarded. The teeth examined under stereomicroscope (Hamilton by AITAY International Italy) at a magnification level of X 20 to excluded the root with cracks or fractures. Bucco-lingual and mesio-distal radiograph were taken for determining root canal morphology. The tooth crown was removed with diamond wheel saw (KG Sorensen SP, Brazil) mounted in a low speed headpiece with water coolant, and the root length adjusted to $12 \mathrm{~mm}$.

The roots were randomly divided into four groups as the following:

Control-ve Group: ( $\mathrm{n}=10)$ the root canals in this group were left intact.

Hand Group: $(n=30)$ the root canals in this group were instrumented using step-back technique with hand stainless-steel $\mathrm{K}$-files.

ProTaper Group: $(n=30)$ the root canals in this group were instrumented using crown-down technique with ProTaper rotary NiTi files.

Helix Group: $(n=30)$ the root canals in this group were instrumented using crown-down technique with Helix 0.06 taper rotary NiTi files.

\section{Instrumentation}

Proper access was established and the apical potency was determined by using ISO \#08 K-file until it appeared at the apical foramen. Working length was determined by placing a size $10 \mathrm{~K}$-file into the canal until it appeared at the apical foramen. This length subtracted by $0.5 \mathrm{~mm}$ was considered the working length. The Hand, ProTaper, Helix groups were prepared according to the following techniques. ${ }^{(12)}$

Hand Group: instrumented using step-back technique with standardized stainless steel files. The cervical third of the root flare with Gates-Glidden drill (size 2 and 3). Then canals were prepared by ISO 0.02 taper hand stainless steel k-files(MAN, ICN. JAPAN) to size \#30 as the master apical file(MAF). This was followed by hand filing to master apical file and then step-back in $1 \mathrm{~mm}$ increments for three additional file sizes. Recapitulation with the master apical file at the working length was carried out after each step back size file.

Protaper Group: instrumented using crown-down technique with Protaper rotary NiTi files. The canals were prepared with Protaper nickel titanium instruments (Densply, Swiss) using nickel titanium control hand piece (Endo-Mate DT, NSK NAKANISHI, INC., JAPAN) at speed of $300 \mathrm{rpm}$ and torque $3 \mathrm{Nm}$. Shaping was started with the shaper S1 using multiple passive-pressure passes to the anticipated 
working length. Using S1followed by S2, the preparation was extended to predetermined working length. Apical third of the canal was finished using finishing file F1, F2 followed by F3 to predetermined the working length.

Helix Group: All teeth in this group prepared using Helix rotary $\mathrm{NiTi}$ files (Diadent, Korea) to (size 30, 0.6\% taper) using crown down preparation technique according to manufacture instruction. A total of 4 instruments were used with nickel titanium control hand piece (Endo-Mate DT, NSK NAKANISHI, INC., JAPAN) at rotational speed of 300 rpm and torque (3 Nm). Preparation of the canal begin by using (a size \#45, 0.6\% taper) then irrigate to remove debris and recapitulated the canal. complete the root preparation with a size 40\#, 35\# and finally a size \#30 file used up to the working length, which represent the master apical file..

The master apical file size was kept constant for all groups as\#30.Throughout the instrumentation procedure, all canals were irrigated using $2 \mathrm{ml}$ of $2.5 \%$ sodium hypochlorite and recapitulation with an Iso \# 10K-file was done after every instrument used. After completion of canal preparation, the canals were rinsed with 5 $\mathrm{ml} 15 \%$ ethylenediamine tetra-acetic acid (EDTA) to minimize the residual effect of $\mathrm{NaOCl}$ on free radical polymerization ${ }^{(13)}$. A final rinse of $5 \mathrm{ml}$ distilled water was used to remove any remnant of the irrigating solution. Canals were dried using paper points. The teeth were kept moist at all times by wrapping them in saline soaked gauze.

\section{Obturation}

Hand Group, Protaper Group and Helix Group subdivided into three subgroups $A, B$, and $C(n=10)$ according to the obturation technique as follow:

Hand A, Protaper A and Helix A groups: control +ve (left with outobturation).

Hand B, Protaper B and Helix B groups: obturated using Cold Lateral condensation technique.

Hand C, Protaper C and Helix C groups: obturated using Thermafil Obturation technique.
Tgadseal root canal sealer (Technical \& General LTD. London-United Kindom) was used as a sealer and the root canals were obturated as follows:

\section{Cold Lateral Condensation Obturation}

A size 30 gutta-percha cone (Dia-Dent Eurpe B.V. Almere, Netherlands, KOREA) was pre-fitted into the canal at the working length. The canal was dried with paper point and the sealer was mixed according to manufacturer instructions and then applied to the root canal walls with size \# $30 \mathrm{k}$-file. The master cone was placed into the canal at the working length. Lateral condensation was done with corresponding finger then the canal filled with accessory cones size \# 25 . Lateral condensation was completed when the finger spreader could no longer penetrate into the canal. Excess material was seared of and condensed with plugger $1 \mathrm{~mm}$ bellow the canal opening. The canal orifice was sealed with soft wax ${ }^{(14,15)}$.

\section{ThermafilObturation}

A size \#30(Gamma irradiated, DK under US patent No. 5,588,,835) verifier was pre-fitted into the canal at the working length. The same size Thermafilobturator was heated in the Soft-Core ${ }^{\circledR}$ DT oven (CMS Dental. 21G Njalsgade DK-2300 Copenhagens). The canal was dried, and the mixed sealer was applied to the root canal wall with size \# $30 \mathrm{k}$-file. Then the obturator was slowly placed at the working length in a single motion. After the gutta-percha was cooled, the obturator was severed at the canal orifice. Excess material was seared of and condensed with plugger $1 \mathrm{~mm}$ bellow the canal opening. The canal orifice was sealed with soft wax. ${ }^{(14,15)}$

All samples stored in distilled water at $37 \mathrm{C}^{\circ}$ for one week in an incubator to simulate in vivo condition ensuring correct setting of sealing material.

\section{Mounting}

After the incubation period the wax was removed from the canal orifice and all the roots were mounted vertically in self-cure acrylic resin, three millimeters of the root were embedded in the acrylic exposing the remaining $9 \mathrm{~mm}^{(14,16)}$, Figure 
(1). The specimens were mounted on the lower plate of Digital Force Gauge Machine ( Model ZP, Imada Co., LTD. Japan) Figure (2), a loading fixture with a spherical tip $(\mathrm{r}=2 \mathrm{~mm})$ was mounted and aligned with center of the canal of each sample and it inserted into the canal to contact gutta-percha as a means of distributing the load to the canal wall for frac- ture testing (Figure 3), after that each sample was subjected to load at cross speed of $1 \mathrm{~mm} / \mathrm{min}$ until fracture occurred. ${ }^{(14,17)}$ The load at which failure occurred was recorded and express in Newton's. The data were calculated and analyzed statistically using ANOVA and Duncan's multiple range test at $(\mathrm{p}<0.05)$.

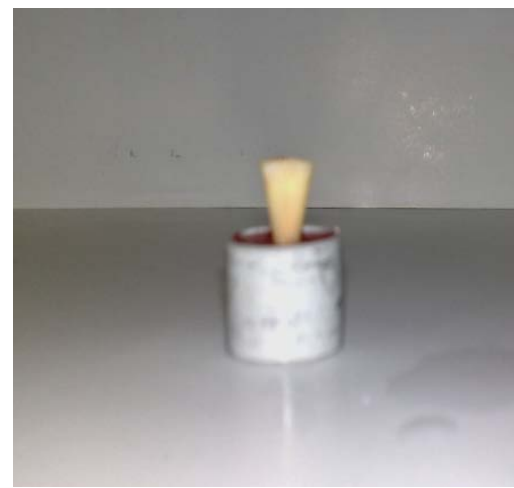

Figure (1): Prepared Sample

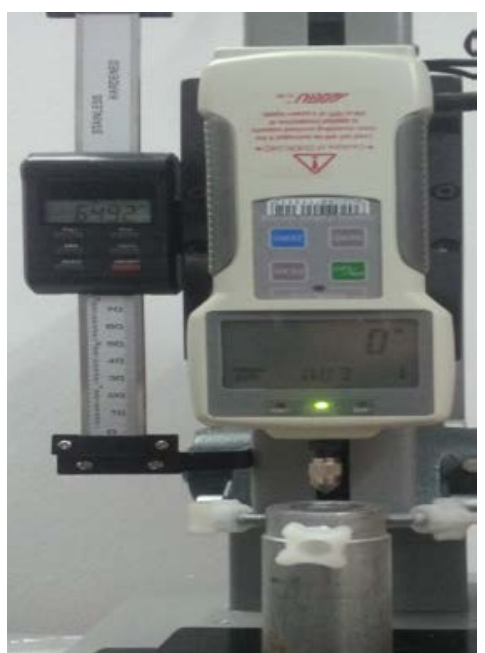

Figure (2): Figital Force Gauge Machine ( Model ZP, Imada Co., LTD. Japan)

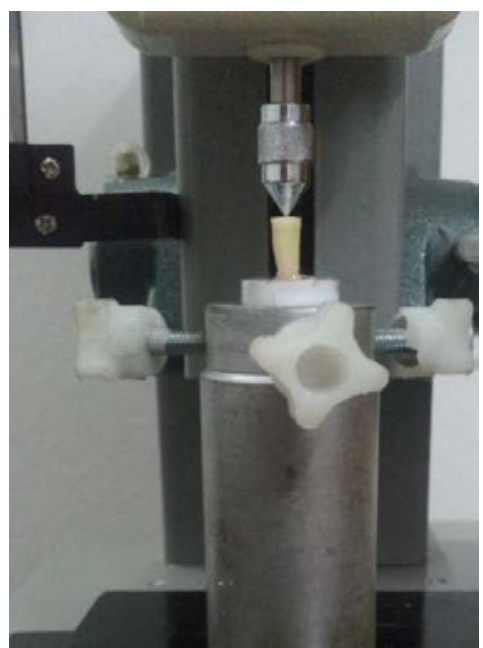

Figure (3):The Specimens were Mounted in the Instron Universal Machine 


\section{RESULTS}

The mean, standard deviation and Duncan's Multiple Range Tests for tested groups are presented in Table(1). Duncan's multiple rang test for the effect of instrumentation types showed that there was a statistically significant difference of maximum load of fracture among groups at $(\mathrm{p}<0.05)$. Duncan's multiple range test (Table 2) showed that ProTaper Groups represent the highest mean of fracture load $(498.89 \pm 133.22) \mathrm{N}$ which was not significantly differented from groups instrumented with Helix file (469.99 \pm 82.40$) \mathrm{N}$. K-file showed the lowest mean load required to fracture the root(274.79 \pm 91.68$) \mathrm{N}$ and the difference was statistically significant when compared with the ProTaper and Helix groups.

Table (1): Mean, Standard Deviation and Duncan's Multiple Range Tests for the Tested Groups

\begin{tabular}{|c|c|c|c|c|c|}
\hline Instrument & obturation & Number & Mean & Std. deviation & $\begin{array}{c}\text { Duncan's } \\
\text { group }\end{array}$ \\
\hline Control & control-ve & 10 & 689.6 & 6.198 & $a^{*}$ \\
\hline \multirow[t]{3}{*}{ Hand } & A & 10 & 322.46 & 97.43 & $\mathrm{f}$ \\
\hline & B & 10 & 187.50 & 47.35 & $\mathrm{~h}$ \\
\hline & $\mathrm{C}$ & 10 & 314.42 & 16.49 & g \\
\hline \multirow[t]{3}{*}{ ProTaper } & A & 10 & 592.04 & 68.17 & $\mathrm{~b}$ \\
\hline & B & 10 & 316.42 & 48.72 & gf \\
\hline & $\mathrm{C}$ & 10 & 588.2 & 60.199 & $\mathrm{~b}$ \\
\hline \multirow[t]{3}{*}{ Helix } & A & 10 & 573.12 & 49.58 & c \\
\hline & B & 10 & 358.24 & 22.52 & e \\
\hline & $\mathrm{C}$ & 10 & 514.61 & 34.13 & d \\
\hline
\end{tabular}

* Different letters mean significant differences

$\mathrm{A}=$ control $+\mathrm{ve}, \mathrm{B}=$ obturated use Cold Lateral condensation obturation technique, and $\mathrm{C}=$ obturated use Thermafilobturation technique.

Table (2): Duncan's Multiple Range Tests For The Effect of the type of Instruments on Vertical Root Fracture.

\begin{tabular}{ccccc}
\hline Instrument & Number & Mean & Std. deviation & Duncan's group \\
\hline Control-ve & 10 & 689.6 & 6.198 & $\mathrm{a}^{*}$ \\
Hand & 30 & 274.793 & 91.68 & $\mathrm{C}$ \\
ProTaper & 30 & 498.89 & 133.22 & $\mathrm{~b}$ \\
Helix & 30 & 469.99 & 82.40 & $\mathrm{~b}$ \\
\hline
\end{tabular}

* Different letters mean significant differences.

Duncan's multiple rang test for the effect of obturation techniques, showed that there was difference in the mean of the fracture load among the groups. Duncan's multiple rang test (Table 3) showed that the groups obturated with Thermafil had higher mean of fracture load $(487.87 \pm 62.53) \mathrm{N}$ than Cold lateral Condensation technique which showed the lowest mean load required to fracture the root $(287.39 \pm 59.10) \mathrm{N}$ but the difference between the two groups was not statistically significant. The most of the fracture lines in all groups were in bucco-lingual direction (Figure 4), followed by root fracturing in the proximal direction and then compound fracture(Table 4). 
Table (3): Duncan's Multiple Range Tests for The Effect of the Obturation on Vertical Root Fracture.

\begin{tabular}{ccccc}
\hline Obturation & Number & Mean & Std. deviation & Duncan's group \\
\hline Control-ve & 10 & 689.6 & 6.198 & $\mathrm{~A}^{*}$ \\
A & 30 & 483.87 & 100.73 & $\mathrm{~b}$ \\
B & 30 & 287.39 & 52.86 & $\mathrm{C}$ \\
C & 30 & 487.87 & 62.53 & $\mathrm{~b}$ \\
\hline
\end{tabular}

* Different letters mean significant differences

$\mathrm{A}=$ control $+\mathrm{ve}, \mathrm{B}=$ obturated use Cold Lateral condensation obturation technique, and $\mathrm{C}=$ obturated use Thermafilobturation technique.

Table (4): Direction Of The Fracture Among the Groups.

\begin{tabular}{|c|c|c|c|c|}
\hline Instrumen & Obturation & Bucco-lingual & Proximal & Compound \\
\hline Control & control-ve & 9 & 1 & - \\
\hline \multirow[t]{3}{*}{ Hand } & A & 8 & 1 & 1 \\
\hline & B & 9 & 1 & - \\
\hline & $\mathrm{C}$ & 9 & - & 1 \\
\hline \multirow[t]{3}{*}{ ProTaper } & A & 9 & 1 & - \\
\hline & B & 10 & - & - \\
\hline & C & 10 & - & - \\
\hline \multirow[t]{3}{*}{ Helix } & A & 8 & 1 & 1 \\
\hline & B & 9 & - & 1 \\
\hline & C & 9 & 1 & - \\
\hline
\end{tabular}

$\mathrm{A}=$ control $+\mathrm{ve}, \mathrm{B}=$ obturated use Cold Lateral condensation obturation technique, and $\mathrm{C}=$ obturated use Thermafilobturation technique.

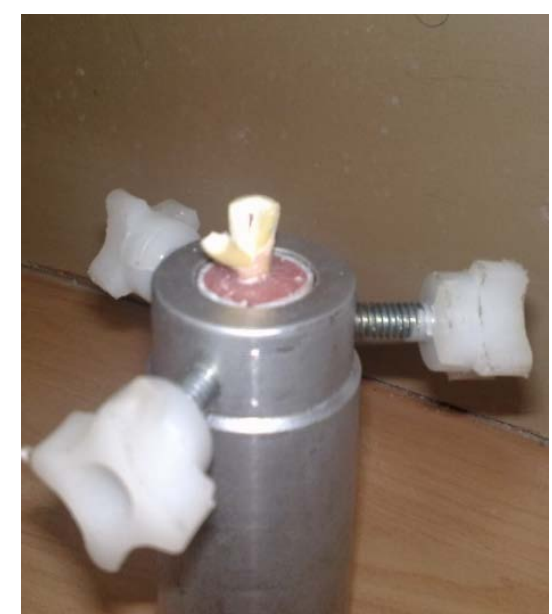

Figure (4): Fractured Sample

\section{DISCUSSION}

Complete or incomplete VRFs constitute an ongoing problem in dentistry, because they are difficult to diagnose in the early stages. In most cases, tooth extraction is the only reasonable treatment when the VRF is finally diagnosed. ${ }^{(18)}$ As root canal therapy has become well established as a viable clinical treatment to retain a tooth, they are generally accepted that several endodontic procedures such as access preparation, instrumentation and even irrigation lead to reduction in fracture resistance of instrumented teeth. ${ }^{(19,20)}$

The result of this study showed that 
non prepared group had higher resistance to VRFs than prepared unfilled groups. Studies showed that preparation weakens roots and makes teeth susceptible to vertical fracture is supported by previous studies. $^{(21,22)}$

In this study, canals prepared with step-back technique using standardized K-files created a taper of 0.02 in the apical third of the canal, whereas Helix rotary NiTi files created taper of 0.06 , while the ProTaper variable taper within the same file. The ProTaper created a taper of 0.09 in apical third of the canal.

Although larger size preparation of root canal was obtained by Helix and ProTaper compared to K-files, the fracture resistance of the root canal prepared by Helix and ProTaper files were significantly greater than that obtained for the root canals prepared with K-files. This finding is contrary to the study by Wilcox et al., and Zandbiglari et al., which concluded that the more root dentin was removed, the more likely a root was to fracture. ${ }^{(19,23)}$ This may be due to the more rounder canal shapes obtained by preparation with ProTaper and Helix files, which leading to reduced areas of stress concentration which allow even distribution of force inside a root canal, and this finding supported by previous study. ${ }^{(12,24)}$

The results of this study also demonstrated that roots obturated with Thermafil resist the fracture load more than that of the roots obturated with Cold Lateral condensation obturation but the different is not significant. This may be due to the excessive force during lateral condensation. $^{(2,18)}$

This study showed that most fracture lines were occurred in a bucco-lingual direction. The mechanism of bucco-lingual fracture was proposed by Lertch-irakarn et al. ${ }^{(25)}$, who stated that when pressure is applied in a thick walled vessel stresses are of two types: tensile stress in a circumferential direction and compressive stress in the radial direction. The thin (proximal) part of the wall will be forced to expand more readily than the thick (bucco-lingual) part of the wall in a radial direction. The asymmetrical expansion creates additional circumferential tensile stresses on the inner surface of the thicker areas, resulting from the outward bending of the thinner part of the dentin wall. The most important factors which potentially influence the location and direction of fracture lines is the root canal shape with a reduced radius of curvature, the external root morphology and dentin thickness. Studies found that oval root canal is more susceptible to high stress than a more circular one and fracture occurs when the tensile stress in the canal wall exceeds the ultimate tensile strength of dentin. ${ }^{(12,25)}$

\section{CONCLUSIONS}

Under the limitation of this study, the results represented that:

1. The use of rotary nickel titanium files in endodontic treatment provides higher fracture resistance for the roots than hand instrumentation.

2. Thermafil Obturations increase the resistance to vertical root fracture when compared with Cold lateral condensation Obturation.

3. Most of the fracture lines observed in bucco-lingual direction.

\section{REFERENCES}

1. Hanada T, Quevedo C, Okitsu M, Yoshioka T, Iwasaki N, Takahashi H, Suda $\mathrm{H}$. Effects of new adhesive resin root canal filling material on vertical root fractures. Aust Endod $J$. 2010;36:19-23.

2. Lertchirakarn V, Palamara J, Messer H. Load and strain during condensation and vertical root fracture. $J$ Endod. 1999;25:99-104.

3. Trope M, Maltz D, Tronstad L. Resistance to fracture of restored endodontically treated teeth. Endodo Dent Traumatol 1985; 1:108-129.

4. Meister F, Lommel T, Gerstein H. Diagnosis and possible causes of vertical root fractures. Oral Surg Oral Med Oral Pathol Oral Radiol Endod. 1980; 49:243-296.

5. Thompson SA. An over view of nickel titanium alloys used in dentistry. Int 
Endod J.2000;33:297-310.

6. Thompson SA, Dammer P. Shaping ability of rotary nickel titanium instruments in simulated root canals. Int Endod. J 1997;30:262-269.

7. Inan U, Aydin C, Tunca Y, Basak F. In vitro evaluation of matched-taper single-cone obturation with fluid filtration method. JADA. 2009; 75: 123-123.

8. Wilcox LR, Roskelley C, Sutton T. The relationship of root canal enlargement to finger spreader induced vertical root fracture. J Endo. 1997;23:233-237.

9. Dang DA, Walton RB. Vertical root fracture and root distortion: effect of spreader design. J Endod. 1998;15:294301.

10.Dalat D, Spangberg L. Comparison of apical leakage in root canals obturated with various guttapercha technique using dye vacuum tracing method. $J$ Endod.1994;20:315-324.

11.Ozok AR, Vander Sluis W. Sealing ability of new poly dimethylsiloxane based root canal filling material. $J$ Endod.2008;34: 204-211.

12.Hegde M, Shetty S, Godara N. Evaluation of fracture strength of tooth root following canal preparation by hand and rotary instrumentation- An invtro study. Endodod.2009:2:22-29

13.Grand N, Plotino G, Falanga A, PomponiM,Somma F. Interaction between EDTA and Sodium hypochlorite: A nuclear magnatic.resonance analysis. $J$ Endod 2006; 32:460-464.

14.Kazandag M, Sunay H, Bayirli T. Fracture resistance of roots using different canal filling systems. Inter. Endo J.2009; 42:705-710.

15.Inan U, Aydin C, Tunca Y, Basak F. In vitro evaluation of matched-taper single-cone obturation with fluid filtration method. JADA. 2009; 75: 123-123.

16.Apicella M, Loushine R, West L, Ru- nyan D. A comparson of root fracture resistance using two root canal sealers. Inter. Endo J.1999; 32:370-380.

17.Baba S, Grover S, Tyagi V. Fracture resistance of teeth obturated with Guttapercha and Resilon: An in vitro study. J Conserv Dent. 2010;32, 61-64.

18.Cohen S, Blanco l, Berma l. Vertical root fractures Clinical and radiographic diagnosis. JADA.2003; 134:434-441.

19.Zandbiglari T. Davids H, Schafer E. Influence of instrument taper on the resistance to fracture of endodontically treated roots. Oral Surg, Oral Med, Oral Patho Oral Radio. 2006; 101: 126 -131 .

20.Wadhwani K, Gurung S. Evaluation of root canal sealers on the fracture resistance of root canal treated teethAninvitro study. Endod.2009, 95:5358.

21.Topcuoglu H, Arslan H, Keles A, Koseoglu M. Fracture resistance of roots filled with three different obturation techniques. Med Oral Patol Cir Bucal 2012;17:528-240.

22.KarapinarM,Sunay H, Tanalp J, Bayirli G. Fracture resistance of roots using different canal filling systems. Int Endod J 2009; 42:705-715.

23.Wilcox LR, Roskelly C, Sutton. The relationship of root canal enlargement to finger- spreader induce vertical root fracture. $J$ Endod 1997; 23:533-534.

24.Versluis A, Messer HH, Pintado MR. Changes in compaction stress distributions in roots resulting from canal preparation. Int Endod J.2006; 39: 9319.

25.Lertchirakarn V, Palamara JEA, Messer HH. Patterns of vertical root fracture: factors affecting stress distribution in the root canal. $J$ Endod. 2003;29:523-528. 